\title{
Charles Baudelaire, Spleen parigino. Prose poetiche
}

\section{Mario Richter}

\section{(2) OpenEdition}

\section{Journals}

\section{Edizione digitale}

URL: http://journals.openedition.org/studifrancesi/548

DOI: 10.4000/studifrancesi.548

ISSN: 2421-5856

\section{Editore}

Rosenberg \& Sellier

\section{Edizione cartacea}

Data di pubblicazione: 1 aprile 2015

Paginazione: 177

ISSN: 0039-2944

\section{Notizia bibliografica digitale}

Mario Richter, "Charles Baudelaire, Spleen parigino. Prose poetiche», Studi Francesi [Online], 175 (LIX I

I) | 2015, online dal 01 avril 2015, consultato il 18 septembre 2020. URL : http://

journals.openedition.org/studifrancesi/548; DOI : https://doi.org/10.4000/studifrancesi.548

\section{Questo documento è stato generato automaticamente il 18 settembre 2020.}

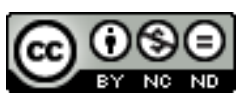

Studi Francesi è distribuita con Licenza Creative Commons Attribuzione - Non commerciale - Non opere derivate 4.0 Internazionale. 


\title{
Charles Baudelaire, Spleen parigino. Prose poetiche
}

\author{
Mario Richter
}

\section{NOTIZIA}

CHARLES BAUDELAIRE, Spleen parigino. Prose poetiche, traduzione e cura di Angelo ARIEMMA, Roma, Edizioni scientifiche Ma.Gi, 2013, pp. 145.

Con indubbia pertinenza Tito Baldini, prefatore di questa nuova traduzione del baudelairiano Spleen de Paris, osserva che «testi importanti 'vivono organicamente' per sempre, si modificano, si adattano ai tempi, alla psicologia dei popoli e anche a quella degli appassionati curatori-traduttori» (p. 15). E il traduttore ribadisce poi che «c'è sempre bisogno di rinnovellare i classici, di portarli a una dimensione di lettura più attuale, più nostra» (p. 19). Appare così legittimato il suo lodevole impegno a «rendere viva la parola scritta più di cento anni fa». Ciò lo porta anche «a scelte a volte più crude, altre più ritmiche e musicali» (p. 19) e a «...co-sentire col testo scelto, per arrivare a desumerne nuova luce, nuovo senso» (p. 20). Il testo risulta infatti assai meditato, ed è efficacemente trasferito in una organizzazione del discorso gradevolmente adattata, fin dal titolo (Spleen parigino), al gusto propriamente italiano e spesso felicemente personalizzata secondo le esigenze esistenziali e poetiche del traduttore. Il prefatore ci fa sapere che Ariemma, suo amico fin dagli anni universitari, si è dedicato a questo lavoro di traduzione in «tappe evolutive [...] da poco più che adolescente a uomo maturo». C'è da supporre che questa origine quasi adolescenziale della traduzione abbia lasciato nell'autore qualche erroneo residuo, dato per certo senza necessità di ulteriori verifiche, ossia una lettura fin dall'inizio affidata soltanto (magari suggestivamente) alla prossimità di un significante che tuttavia ha nelle due lingue un ben diverso significato. Mi riferisco al termine catin dell'Epilogue, che Ariemma traduce con catino (p. 144). In realtà catin è un sostantivo femminile che non ha nulla in comune con l'italiano catino e che, provenendo da un diminutivo di Catherine, ha assunto il 
corrente significato (come anche assicura Bescherelle, contemporaneo di Baudelaire) di "femme ou fille de mauvaises mœurs". 